\title{
O ESTRANGEIRO E A SUA ABSURDIDADE
}

Celso Augusto Nunes da Conceição ${ }^{1}$ Ângela KRETSCHMANN ${ }^{2}$

\begin{abstract}
Resumo: O pensamento contrassensual ou inconsistente sempre causa desconforto intelectual quando uma decisão foge ao bom senso de qualquer situação. É justamente do que trata a obra "O Estrangeiro", de Albert Camus, em que o personagem principal foi condenado não pelo seu crime, mas pela sua conduta social. E como recentemente o Brasil aplicou o Acordo Ortográfico de 2009, mesmo sabendo que os outros países lusófonos ainda o estão discutindo, a relação entre a obra e esse "(des)acordo" hibridiza tanto a expressão "estrangeiro" como os absurdos ocorridos nos dois casos. A partir disso, é possível apresentar o percurso de ambos e as suas vicissitudes que geraram os argumentos falaciosos constituintes das absurdidades.
\end{abstract}

Palavras-chaves: Estrangeiro, Absurdo, Falácia

\begin{abstract}
The dissent or inconsistent thinking always causes intellectual distress when a decision is beyond the common sense in any situation. It is precisely what the book "The Stranger" written by Albert Camus show us, where the main character was convicted not for his crime, but by their social conduct. And as recently Brazil applied the 2009 Orthographic Agreement, even though the other Portuguese-speaking countries still are discussing it, the relationship between the work and that "(dis)agreement" hybridizes both "foreign" words as the absurdities occurred in two cases. From this, it is possibly to display the route of both which led to the fallacious arguments constituents of absurdities.
\end{abstract}

Keywords: Stranger, Absurd, Fallacy

Sumário: Introdução; 1. A absurdidade; 2. Percurso do "estrangeiro" na obra de Camus; 3. Experiência ontológica de um "estrangeiro" brasileiro em Portugal; Considerações finais; Referências bibliográficas.

\footnotetext{
${ }^{1}$ Professor das disciplinas de Português Jurídico e Direito e Linguagem no Cesuca, Mestre e Doutor em Linguística Aplicada na PUCRS e atualmente finalizando o Pós-Doutorado na Faculdade de Direito da Universidade Nova de Lisboa.

${ }^{2}$ Professora e diretora de pesquisa do Complexo de Ensino Superior de Cachoeirinha/RS (Cesuca). Mestre em Direito pela Pontifícia Universidade Católica do Rio Grande do Sul (PUCRS). Doutora em Direito pela Universidade do Vale do Rio dos Sinos (Unisinos/RS). Pós-doutora pelo Institut for Information, Telecommunication and Media Law (ITM), Münster, Alemanha. Professora do Mestrado em Direito da Empresa e Negócios da Unisinos.
} 


\section{INTRODUÇÃO}

Propositadamente, a expressão "o estrangeiro" no título deste artigo não oferece destaque para que se estabeleça, no mínimo, duplo sentido: a obra de Albert Camus, "O Estrangeiro", e o percurso de uma mudança ortográfica denominada "Acordo" em solo brasileiro, sem que o povo pudesse anuir com tal "estrangeirismo". Os contextos são distintos, os absurdos se repetem sem cessar.

O ponto comum entre esses "estrangeiros" é a absurdidade cometida pelas autoridades de órgãos públicos e privados, em que o primeiro se refere à área jurídica, e o segundo a um poder dito autônomo. Sendo mais preciso nas referências desses dois órgãos, um cometerá o absurdo de condenar alguém por um crime com base em questões de comportamento, morais e culturais (ou seja, o homicídio é investigado a partir do comportamento "absurdo" de alheamento do personagem principal em relação a sentimentos que a comunidade exigia que ele sentisse e expressasse), enquanto que o outro provocará o absurdo de implantar uma reforma ortográfica sem a anuência de quem realmente precisaria ser ouvido: o povo.

Duas narrações estão no eixo condutor dessa pretensa analogia e convergem para que o elo da contrassensualidade seja percebido na trajetória de vida que esses dois "estrangeiros" têm em comum: o absurdo.

Aparentemente a palavra 'absurdo' é entendida pelas pessoas como "ausência de razão" ${ }^{3}$, mesmo sem o uso de dicionários, ou seja, o significado é depreendido popularmente pelo senso comum. Porém, em um estudo científico, existe a necessidade de adequações conceituais aplicadas a várias áreas do conhecimento. Diante disso, a plurissignificação de 'absurdo', e de suas derivadas, será contemplada por visões teóricas distintas, bem como algumas exemplificações.

\footnotetext{
${ }^{3}$ Segundo Houaiss (2009), a palavra 'razão' significa, na rubrica geral, "faculdade de raciocinar, apreender, compreender, ponderar, julgar; a inteligência"; na filosófica, 1) "faculdade humana da linguagem e do pensamento, voltada para a apreensão cognitiva da realidade, em contraste com a função desempenhada pelos sentidos na captação de percepções imediatas e não refletidas do mundo externo"; 2) "o pensamento moral, em sua função de orientar a conduta humana, prevendo as consequências e avaliando o significado das ações"; e 3) "no cartesianismo, faculdade caracterizada por seu poder de discernimento entre o verdadeiro e o falso, ou o bem e o mal". Esses significados estão como notas de rodapé por não integrarem o escopo do artigo, que trata das absurdidades, o que será explicitamente esclarecido no decorrer de suas exposições.
} 


\section{ABSURDIDADE}

A significação neste artigo é um dos pontos mais relevantes para que seja possível entender o que de fato aconteceu com o protagonista da obra de Camus, Meursault, o argelino que matou um árabe e foi condenado por outro motivo, e com o acadêmico brasileiro que atravessou o oceano Atlântico para fazer conferências sobre o "(Des)acordo ${ }^{4}$ Ortográfico de $2009^{5 "}$ e se deparou com uma das maiores atrocidades linguísticas provocada pela Academia Brasileira de Letras - ABL, o Acordo Ortográfico de 2009, além de se deparar com um Referendo ${ }^{6}$ contra esse próprio acordo, em Portugal.

Etimologicamente, a palavra 'absurdidade' tem origem no latim, significando "som desagradável, cacofonia, proposição contrária à razão, paradoxo, disparate" (HOUAISS, 2009). Com o passar do tempo, as significações foram se alterando à medida de suas relações com o meio social, chegando aos nossos dias com algumas alterações e inclusões, a saber: 1) "qualidade, condição ou estado do que é absurdo"; e 2) "contradição lógica ou inconsistência; absurdo, disparate" (HOUAISS, 2009).

Na filosofia (MARCONDES \& JAPIASSÚ, 2006, p. 2), há pelo menos quatro abordagens acerca da palavra 'absurdo':

1. Aquilo que viola as leis da lógica por ser totalmente contraditório. É distinto do falso, que pode não ser contraditório. Ex.: a existência do movimento perpétuo. A demonstração por absurdo é aquela que demonstra uma proposição tentando provar que sua contraditória conduz a uma consequência manifestamente falsa; ora, de duas proposições contraditórias, se uma é verdadeira, a outra será necessariamente falsa, e vice-versa. Ver Zenão de Eleia;

2. O pai da filosofia do absurdo é Kierkegaard. Em sua oposição ao hegelianismo, ele afirma a impossibilidade de incluir totalmente o

\footnotetext{
${ }^{4}$ Por que o prefixo 'Des' antecedendo a palavra 'acordo'? Porque é uma forma de ironizar a proposta de um acordo que está gerando mais problemas do que propriamente solução para a unificação linguística nos países lusófonos e continua a gerar desentendimentos sem que se preveja a sua resolução. E também pela questão temporal, em que primeiro se estabeleceu o acordo e depois, com exceção do Brasil, os países ainda não o aplicaram-na sua totalidade. Portugal conseguiu, por decreto, aplicar somente aos órgãos públicos, incluindo as escolas do Estado.

${ }^{5} \mathrm{Na}$ verdade, o ano que deu origem às reformas ortográficas é 1990, conforme será relatado a seguir.

6 WORDPRESS. Referendo ao "Acordo Ortográfico de 1990". Disponível em < https://referendoao90.wordpress.com/>. Acesso em 7 jan 2016. 
*indivíduo $^{7}$ (como subjetividade) numa sistemática racional e a necessidade de fundar uma ética religiosa alicerçada na crença de uma transcendência inacessível. O absurdo é a distância da subjetividade relativamente à razão considerada como uma tentativa para estabelecer um sistema racional do mundo: é a distância entre o finito e o infinito, isto é, o lugar do silêncio de Deus.

3. $\mathrm{Na}$ filosofia existencialista, impossibilidade de se justificar racionalmente a existência das coisas e de lhes conferir um sentido. Sarte, ao ligar o absurdo e a existência de Deus, define-o como a impossibilidade, para o homem, de ser o fundamento de sua própria existência: o homem é "uma paixão inútil", destinado a "ex-sistir", a ser ser para além dele mesmo como uma consciência, como um para-si, isto é, um nada; ele está "condenado a ser livre", a ser responsável por seu ser e por sua própria razão de ser.

4. A partir das obras de Camus e de Kafka, fala-se muito do absurdo, notadamente no domínio da moral ou da metafísica, para designar o "incompreensível", o "desprovido de sentido" e o "sem finalidade".

Importante destacar essas fontes de aproximação semântica dos significados com as suas respectivas palavras: o dicionário de itens lexicais da língua portuguesa ${ }^{8}$ e o de termos filosóficos ${ }^{9}$. O primeiro abrange a questão etimológica da palavra desde a sua origem, passando por transformações baseadas nas mudanças culturais de uma dada língua; o segundo, a questão filosófica para restringir a palavra a áreas específicas do conhecimento humano, como também a seus respectivos teóricos. As contextualizações a seguir aproximam essas relações semânticas à irracionalidade de que nossa sociedade é acometida.

\subsection{Lógica do absurdo}

Através de relatos ficcionais, a crônica é um texto literário que extrai do cotidiano imediato personagens e fatos com o propósito de apresentar assuntos sociais de natureza distinta, podendo conter opiniões críticas e até polêmicas. Dito isso, o jornalista Raul Moreau (2005, p. 8-9) elabora a sua crônica relatando um fato vinculado a uma prática

\footnotetext{
${ }^{7}$ (lat. Individuum: corpo indivisível) 1. Tudo aquilo que constitui uma unidade, não podendo ser dividido sem descaracterizar-se como tal. Objeto simples, sem partes. Aquilo que é contável. Algo que possui características próprias que o distinguem das outras coisas. 2. Do ponto de vista do problema dos universais, discute-se se só os particulares (este homem, esta maça) são indivíduos, ou se também os universais, tais como qualidades ou propriedades (a brancura, a justiça), também podem ser considerados indivíduos.
}

${ }^{8}$ (HOUAISS, 2005)

9 (MARCONDES \& JAPIASSÚ, 2006, p. 2) 
jurídica e inicia seu texto perguntando qual o significado da palavra 'absurdo'. Consultados dicionários mais clássicos, responde à sua própria pergunta: "o absurdo é tudo aquilo que é contrário à razão, ao senso comum. Disparatado. Despropositado. Ato impensado".

O autor começa seu relato descrevendo um acontecimento no município paulista de Biritiba Mirim, região protegida por lei ambiental em virtude de haver muitos riachos e vertentes cristilina, Diz que a cidade poderia se transformar num grande jardim botânico. Mas toda essa fartura gerou, por parte do Conselho Nacional do Meio Ambiente CONAMA, várias proibições, dentre as quais a mais polêmica: "construir cemitérios", criando um grande problema para o prefeito da cidade, que conhece a Lei Natural de que "Quem está vivo, um dia morrerá". Instala-se aí um grande dilema: "como morrer em Biritiba Mirim se lá é proibido construir cemitérios?", quase um paradoxo. Tentou driblar a proibição de várias maneiras, mas todas infrutíferas.

Para resolver esse absurdo, o prefeito encaminhou à Câmara Municipal um projeto que proíbe os habitantes de morrer, recebendo qualificações como 'impossível, impraticável e ilógico". O cronista Moreau $(2005,8-9)$ dá a entender que ele endoidou de vez, mas vai em sua defesa com a seguinte redação:

\footnotetext{
Pois saiba que o Prefeito está mais do que certo ao apelar para uma prática muito usada no Direito, onde e comum a demonstração do absurdo, ou seja, "o raciocínio que prova a verdade de uma proposição, provando o absurdo da proposião contrária”. Em outras palavras, o desesperado e iluminado Roberto Pereria da Silva, Prefeito do céu-inferno (não é mesmo?), respondeu ao CONAMA que, para vencer um doido, só um doido e meio.
}

Ele ainda faz uma provocação quando diz aos leitores que não concordam com o prefeito: "alerto que a solução restante seria mudar a cidade de lugar", mantendo a coerência em sua crônica para que a absurdidade seja bem entendida, tanto pelo lado do prefeito, seu personagem, como pelo de si mesmo. 


\subsection{Falácias ${ }^{10}$}

A falácia é um argumento baseado em formas lógicas, mas que são alteradas em suas regras para se chegar a conclusões aparentemente irrefutáveis, chamada também de sofisma. O discurso persuasivo pode conter esse tipo de argumentação, muito comum nas decisões judiciais. Podem acontecer de forma intencional ou inadvertida sendo plausível ou não.

A plausibilidade está presente na obra de Camus, não pelo protagonista, mas pelos "homens da lei". Destaca-se que o sistema sempre é passível de "muitos argumentos", e isso pode ser decorrência do próprio Estado Democrático de Direito. Entretanto, é necessário lembrar que há uma integralidade do direito, que fundamenta-se em princípios inscritos em uma Constituição Federal, e como já foi dito, uma "muito palpável Constituição Federal, que possui uma história própria, dentro de uma história constitucional" ${ }^{, 1}$ e de um marco histórico de um Estado que passou por diversas crises de poder.

O jurista Luís Alberto Warat (1985) apresenta, em seu artigo, algumas falácias jurídicas, que constituem os absurdos judiciais tão comuns em qualquer sociedade. E afirma que

\footnotetext{
“O uso das diversas classes de falácias, no discurso jurídico, varia segundo seu conteúdo e nível em que aparece. As falácias formais podem aparecer em qualquer discurso, portanto, também no discurso jurídico. Elas são cometidas muitas vezes por ignorância, erro ou por simples inadvertência, o que não exclui a possibilidade de que se apele às mesmas deliberadamente, com fins persuasivos, produzindo significações alternativas, através de transgressão das regras de derivação. Tal situação pode produzir-se em qualquer discurso jurídico. O uso das falácias formais pode dar-se nas apresentações dos letrados, nas sentenças judiciais e nas disposições legais.
}

\footnotetext{
${ }^{10} \mathrm{Na}$ filosofia contemporânea, há três falácias que se distinguem pela sua natureza: 1. Falácia da falácia naturista; 2. A falácia nos atos de fala; e 3. A falácia da asserção.

${ }^{11}$ KRETSCHMANN, Angela; WIEDEMANN, Ney. Argumentação Jurídica IN KRETSCHMANN, Angela, Org. Formação Jurídica II. Florianópolis, 2014. p. 53.
} 
Destaca ainda que "a nível da prática forense, é óbvio que os advogados fazem um grande uso das falácias não formais em defesa dos interesses de sua pátria”. Pode parecer absurdo em se tratando de "justiça", mas a obra de Camus deixa clara a existência desse tipo de insensatez.

Para exemplificar a relação da falácia com esses dois estrangeiros, pode-se ressaltar primeiramente o que aconteceu com Mersault: sentença condenatória pelo crime de ser insensível e não o de ter matado alguém; quanto ao estrangeiro além-mar: a percepção de que a justificativa da $\mathrm{ABL}$, alegando simplificação da ortografia dos países lusófonos, é falaciosa diante das diferenças culturais de cada país, o que aumentou em muito os problemas linguísticos.

E a falácia é a mídia brasileira afirmar que o acordo já está em vigência em Portugal. Está sim, mas somente por decreto aos órgãos públicos e escolas públicas, que foram obrigados por autoritarismo e arbitrariedade. Editoras, universidades e outras empresas particulares estão contrariamente à sua implantação. Em Portugal ainda há esperança de reversão, mas no Brasil já está sacramentado.

\subsection{Absurdos linguísticos}

Em 2009, começam os problemas: o que era para ser acordo, transforma-se em (des)acordo, porque a comunidade de Portugal, principalmente através da Academia das Ciências de Lisboa, questiona várias incongruências. E, no Brasil, a população começa a ficar desnorteada. O que mudou? Perguntam! E por quê? Era necessário? Vai ajudar para escrevermos melhor?

Como "acordos ortográficos" têm validade de quatro anos, a ortografia anterior é aceita por esse período sem que seja considerada erro, mantendo as duas paralelamente. A previsão era para janeiro de 2013 entrar em vigência sozinho. Um decreto três dias antes, precisamente no dia 27 de dezembro de 2012, adiou a vigência do Acordo por mais três anos a fim de que a sociedade tivesse tempo para se atualizar. 
Final de 2015, muita apreensão por parte da população brasileira, principalmente a educacional, porque a maioria dos professores ainda não conhecia as mudanças ortográficas. A esperança de um novo decreto existia, mas, tanto a ABL quanto o governo sabiam que esse acordo estava provocando, no mínimo, mal estar na sociedade. Inclusive, havia uma comissão no Senado para discutir esse assunto, precisamente nos dias 21 e 22 de outubro de 2014, tendo a ABL, através do professor Bechara, comparecido às duas reuniões para explicar e debater com os especialistas em língua portuguesa. Os vídeos desses encontros estão na internet. Pensava-se que a partir dali a população receberia de presente um retorno ao que não deveria ter sido alterado. O que aconteceu depois? Ninguém sabe!

No dia primeiro de janeiro de 2016 entraram em vigor as novas regras, mesmo com todos os problemas de conhecimento dos que decidem e da própria mídia, omissa ou coniventar. Academia não intercede para que o acordo seja adiado, ...

Efetivamente, o que mudou nas regras ortográficas?

Houve alteração no trema, ditongos abertos, hiatos, hífen. E praticamente todas elas já estão registrados no VOLP ${ }^{12}$ - Vocabulário Ortográfico da Língua Portuguesa, que são diferentes no Brasil, Portugal e noutros países lusófonos.

Uma das características VOLP é tornar oficial qualquer palavra do uso comum. Se ela já estiver sendo utilizada pela sociedade, ela é formalmente registrada. O problema é quanto aos critérios envolvidos para que isso aconteça.

Por exemplo, no sul do país há uma palavra que é produzida pelos gaúchos: 'ciclano', uma variação de 'sicrano'. Normalmente casos como esse não são incorporados porque "corrompem" a língua portuguesa, segundo alguns gramáticos, chamados de puristas da língua. Esse é um caso estranho porque há uma palavra grafada desta forma, mas que existe representando a combinação de duas substâncias químicas. Então podemos inferir que a palavra produzida pelos gaúchos existe, mas pode não estar lá, existe e pode estar lá por entenderem que o registro foi adequado, e que existe e pode estar lá por coincidência à outra da área da química.

Outra situação é quanto à palavra 'gratuito', considerada como ditongo na sua pronúncia, mas a maioria do povo brasileiro fala de forma hiatizada, ou seja, coloca a

\footnotetext{
${ }^{12}$ Está disponível também no site da Academia Brasileira de Letras (2009). Ressalta-se que há muitos erros nas alterações que não foram revistas antes da inclusão no VOLP.
} 
tonicidade somente na vogal 'i'. Este já é um caso existencial melhor entendido porque a palavra existe na comunidade brasileira com a pronúncia hiatizada. Por que ainda não foi registrada no VOLP? Absurdo, descaso ou incompetência? Ou o quê?

Em linhas gerais, o trema não é mais utilizado, com exceção dos topônimos e antropônimos; eliminaram os acentos nos ditongos abertos que estão nas paroxítonas; eliminaram o acento no hiato tônico quando precedido de ditongo; e o hífen continua infernizando a vida do cidadão brasileiro, constituindo-se em um capítulo à parte.

Além das outras mudanças, os lexicógrafos da Academia Brasileira de Letras resolveram estabelecer critério semântico para a eliminação do hífen: as palavras compostas por justaposição podem dar lugar à aglutinação. Antes da reforma, escrevia-se "pára-quedas" com hífen para manter a integridade das palavras. Agora 'paraquedas' é uma palavra não mais composta por suas partes. Seguindo essa mesma lógica, a palavra 'guarda-chuva deveria ter o seu hífen retirado? Deveria, até porque, se fosse para guardar a chuva, a sua forma deveria ser côncava e não convexa. Outras incongruências desse tipo também aconteceram.

\section{O PERCURSO DO “ESTRANGEIRO” NA OBRA DE CAMUS}

Protagonista da obra de Camus, Meursalt é um estrangeiro francês que trabalha em um escritório na Argélia. Foi chamado para uma cidade próxima em função do falecimento de sua mãe, que morava em um asilo de velhos. Chegando no velório, aparentemente não manifesta qualquer emoção, deixando transparecer às pessoas que ali estavam um comportamento nada convencional, como se fosse desprovido de sensibilidade. Já recebera a primeira tácita condenação. No outro dia, vai ao enterro de sua mãe, manifestando igual comportamento do dia anterior, a indiferença diante dos fatos.

No domingo, Meursault toma banho de praia com uma antiga datilógrafa do escritório em que trabalhava. Ela quer casar com ele e faz o pedido. Ele aceita sem demonstrar alguma afetividade amorosa, ou seja, aceita o casamento mesmo sem a amar. Esses fatos vão acontecendo sob os olhares do pessoal da região. Sem dúvida, suas atitudes são consideradas estranhas e absurdas. 
No seu prédio, convive com um vizinho de porta. A narrativa não define a relação como amizade, somente conhecidos. Esse vizinho se envolveu em uma briga com árabes, levando a pior. Depois de um certo tempo, os dois andavam pela praia e avistaram os tais árabes. Meursault pede o revolver do vizinho para que lutassem como homens, mas um dos árabes faz um movimento de que iria pegar algo, era uma navalha. Mersault pega o revólver e, vendo que o árabe a estava usando, desfere um tiro e em seguida mais quatro. Oito dias depois foi preso.

Começa a fase processual em que o "estrangeiro", insensível aos acontecimentos, é chamado a responder perguntas ao promotor. A partir daqui, há uma recorrência à história para apresentar de fato uma reflexão sobre o absurdo. $\mathrm{O}$ promotor tenta provar que o homem que não chora pela morte de sua própria mãe é culpado de tudo. Mersault se despreocupa perante tal inquisição, o que deixa o advogado perplexo. Na verdade, parece que o "estrangeiro" se resigna a aceitar a condução do processo por entender que nada pode fazer em uma sociedade que já carrega suas premissas para os comportamentos das pessoas.

Seu advogado ainda tenta ajudá-lo, mas em vão. E já no julgamento, na hora da sentença, Mersault reflete sobre sua condição:

\footnotetext{
Portas bateram. Pessoas corriam pelas escadas, não sei se longe ou se perto de onde eu estava. Depois ouvi uma voz surda ler qualquer coisa na sala. Quando a campainha soou novamente e a porta se abriu, foi o silêncio da sala que chegou até mim, o silêncio, e aquela sensação singular que experimentei ao constatar que o jovem jornalista tinha desviado o olhar. Não olhei para o lado de Marie. Aliás não tive tempo pois o presidente me disse de um modo bizarro que me cortariam a cabeça numa praça pública em nome do povo francês. (CAMUS, 1977, P. 108)
}

Diz-se que ele fica alheio a tudo, que é insensível, que não interage com o meio, mas o que dizer dessa sua reflexão? Certamente ele tinha consciência da absurdidade dos acontecimentos.

\section{EXPERIÊNCIA ONTOLÓGICA DE UM "ESTRANGEIRO" BRASILEIRO EM PORTUGAL}


Em janeiro de 2015, um "estrangeiro" chegou em Portugal para fazer contatos com uma Faculdade de Direito a fim de cursar um pós-doutoramento (o primeiro autor deste artigo). Como nesse país a língua oficial é a portuguesa, a impressão que se tem é a de uma fácil comunicação, mas esse estrangeiro ${ }^{13}$ percebeu que há divergência linguística de vários níveis. E aproveitando a oportunidade de estar na terra de Camões, partiu para uma visita à Academia das Ciências de Lisboa ${ }^{14}$ com o objetivo de conversar sobre o famoso “Acordo Ortográfico", que já estava em vigência efetiva desde 2009, mas ainda em período de transição para que a população assimilasse a ideia. Solicitou falar com o Presidente do ILLLP, Dr. Artur Anselmo, e foi prontamente recebido. O foco da conversa foi esse famigerado acordo.

De volta ao Brasil, no início do segundo semestre do mesmo ano, esse brasileiro recebe um convite para apresentar uma conferência no Colóquio "Ortografia e Bom Senso", promovido pela Academia das Ciências de Lisboa ${ }^{15}$. para o mês de novembro ainda do mesmo ano, mas era preciso encaminhar um resumo da conferência. Sob o título de "A unificação da ortografia nos países lusófonos: colapso linguístico", o resumo foi encaminhado e aceito para participação do evento. E lá vai novamente esse brasileiro a embarcar para a terra além-mar, mas não só para isso, também para cursar o seu PósDoutorado na Faculdade de Direito da Universidade Nova de Lisboa e para ministrar um curso de extensão de Português Jurídico, já divulgado e em fase de inscrição.

Essa necessária contextualização prepara os principais sítios ${ }^{16} \mathrm{em}$ que nosso brasileiro irá transitar e onde encontrará dificuldades de comunicabilidade.

No primeiro dia do Colóquio na Academia das Ciências de Lisboa ${ }^{17}$ - ACL, 9 de novembro de 2015, entrava "o estrangeiro" no Salão Nobre, o templo sagrado da

\footnotetext{
${ }^{13}$ Considera-se estrangeiro o "indivíduo de nacionalidade diversa daquela do país onde se encontra ou vive (HOUAISS, 2009)

${ }^{14}$ Esta academia é composta por dois órgãos distintos: o Instituto de Altos Estudos (IAE) e o Instituto de Lexicologia e Lexicografia da Língua Portuguesa (ILLLP)

${ }^{15}$ A página do evento é http://www.acad-ciencias.pt/wordpress/coloquio-sobre-ortografia-e-bom-senso/

${ }^{16}$ Palavra do idioma português de Portugal e que significa: 1. Espaço que um objeto ou pessoa deve ocupar (ex.: vou pôr o livro outra vez no sítio) = lugar; 2. Página ou conjunto de páginas da Internet com informação. (PRIBERAM, 2015)

${ }^{17}$ ACADEMIA DAS CIÊNCIAS DE LISBOA - ACL. Vocabulário Ortográfico Atualizado da Língua Portuguesa. Lisboa: Imprensa Nacional-Casa da Moeda, 2012.
} 
intelectualidade linguística, a cumprimentar alguns dos conhecidos presentes. Sabedor de que encontraria o professor Evanildo Bechara, membro da Academia Brasileira de Letras ABL e também conferencista do evento, foi ao seu encontro para cumprimenta-lo, aproveitando o momento para elogiá-lo pelos seus inestimáveis trabalhos em língua portuguesa, uma longa e consistente caminhada acadêmica. Porém, estavam em lados opostos, considerados de acordistas e antiacordistas pelos portugueses.

Iniciadas as conferências, chega o momento de o professor Bechara proferir a sua conferência sob o título "Por quê o Brasil aceita as normas do Novo Acordo Ortográfico?", posicionando-se pela defesa do acordo, diante da maioria de outras que fazem o inverso. Mas o vocábulo 'quê', constante no título, chama a atenção do leitor atento, que reage com cautela porque sabe quem elaborou o título. E também poderia pensar em erro de digitação ou no absurdo de errar justamente em um evento como esse. Complicado mesmo! E o leitor que neste momento está lendo (ou está a ler) ${ }^{18}$, o que pensa disso? E pode pensar que a regra também pudesse ter sido alterada. Não, a regra não mudou.; foi somente a ortografia $^{19}$, ou seja, somente a grafia, a forma de se escrever a palavra. Quanto àquele 'quê', foi escrito em obediência às regras da sintaxe portuguesa, que são distintas da brasileira em inúmeros aspectos ${ }^{20}$.

No outro dia, nosso brasileiro está novamente assistindo aos seus colegas de conferência. Logo depois é chamado pelo então Presidente da ACL, Dr. Anselmo, que anuncia também o título da conferência: “A unificação da ortografia das nações lusófonas: colapso linguístico". São $35 \mathrm{~min}$ de uma "língua estrangeira" sendo ouvida pela plateia ${ }^{21}$, na sua grande maioria composta de cidadãs e cidadãos portugueses. Eis que, em um determinado momento, alguém, sem microfone, tenta falar alto o suficiente para chamar a atenção do nosso conferencista, que se surpreende com o ocorrido. Prontamente o presidente da mesa, que estava do lado, diz "é prostituta". Ambiguidade à vista na terra de Pedro Álvares Cabral. O leitor deve estar se perguntando se a pessoa que falou tem esse

\footnotetext{
${ }^{18}$ Expressão no infiês, nitivo, caraterística da sintaxe portuguesa; no Brasil, o uso corrente é o gerúndio. 19 Segundo Houaiss (2009), é "conjunto de regras estabelecidas pela gramática normativa que ensina a grafia correta das palavras, o uso de sinais gráficos que destacam vogais tônicas, abertas ou fechadas, processos fonológicos como a crase, os sinais de pontuação esclarecedores de funções sintáticas da língua e motivados por tais funções etc".

${ }^{20}$ Uso dos porquês, gerúndio em vez do infinitivo, colocação pronominal (próclise, mesóclise e ênclise), dentre outras.

${ }^{21} \mathrm{O}$ acento nessa palavra foi suprimido na Reforma Ortográfica. 
adjetivo ou é o significado de alguma palavra mal empregada. Foi a essa última! E a palavra foi "pega ${ }^{22 "}$. E agora, mal empregada? Considera-se absurdo esse fato? Como nosso estrangeiro tratou do caso?

Foi com um sorriso e com o ar de quem aprendeu mais uma palavra, prontamente se justificou: “estudei muito o que não deveria dizer, mas fui 'pego' de surpresa, aprendi mais uma"! O "ser" estrangeiro experienciou a diferença cultural em um país que fala a mesma língua. Seria considerada absurda a ideia de que não deveria haver diferenças linguísticas dessa natureza? Possivelmente sim para os leigos.

Seguindo na sua exposição, apresenta um breve histórico dos $\operatorname{acordos}^{23}$, necessário para fundamentar a origem do problema que já se instaurara na vida social e nos meios escolares, encaminhando-se para um colapso linguístico sem precedentes. E começa a apresentar alguns exemplos das "atrocidades linguísticas" 24 da Reforma Ortográfica ${ }^{25}$ de 1990, que estava engavetada na Academia Brasileira de Letras e que, misteriosamente ${ }^{26}$, reapareceu para gerar essa celeuma toda. Certamente mais um caso de absurdo "acadêmico".

Alguns casos de inconsistências e incongruências linguísticas aplicadas pelo "acordo" são exemplificados para sustentar a proposta da "não unificação" da ortografia dos países lusófonos. O principal argumento está nas diferenças idiomáticas entre Portugal e Brasil e não menos importante são as diferenças dialetais manifestadas dentro do próprio país.

Finaliza a sua conferência com afirmações e propostas:

\footnotetext{
${ }^{2222}$ A expressão “foi pega”, responsável pela celeuma, é constituída do verbo auxiliar 'ser' e o particípio irregular do verbo abundante 'pegar'. Como o sujeito era feminino, o particípio obedeceu à regra da concordância, gerando a palavra 'pega', que é sinônimo de prostituta. Na resposta, a expressão 'foi pego' não causou nenhum problema semântico porque 'pego' ficou no masculino, sem correspondência com sinônimo vulgar. Questões linguísticas dessa natureza sempre vão acontecer porque o lugar, não necessariamente país, tem outra cultura, outra identidade e outras expressões.

${ }^{23}$ Mais detalhes em < http://www.fd.unl.pt/Anexos/10386 4.pdf>, CONCEIÇÃO (2015).

${ }^{24}$ Algumas delas foram citadas no artigo de CONCEIÇÃ O\&MOREIRA (2013): O Alienista e o Acordo Ortográfico de 2009: insanidade compartilhada. Disponível em $<$ http://ojs.cesuca.edu.br/index.php/dialogosdodireito/article/view/391/192>. Acesso em 03 jan 2016, p. 188197

${ }^{25}$ Importante diferenciar "Reforma Ortográfica", ajustes da ortografia dentro de um país, da expressão "Acordo Ortográfico", unificação das "reformas" entre países.

${ }^{26}$ Em terras portuguesas, a imprensa local já conhecia o fato, que apresentou fatos denunciando a forma do "desengavetamento" em 2007: novo presidente da ABL queria colocá-la em evidência.
} 


\begin{abstract}
"O patrimônio de Portugal é a língua e o idioma. O Brasil, apesar das tentativas de se "autopromover" à língua brasileira, em função principalmente de sua sintaxe, só tem o idioma como seu patrimônio. Bem, isso já é outro assunto.

Tenho certeza de que a identidade de um povo começa pela língua, que é derivada de sua cultura e idiossincrasias. Diante do exposto neste Colóquio, com vários alertas e possibilidades de caos linguístico, espero que o bom senso predomine em todas as instâncias de decisão, mantendo assim o respeito às diferenças linguístico-culturais de cada país, seja por sua língua, seja por seu idioma".
\end{abstract}

Outras conferências com o foco predominantemente antiacordista justificavam as causas provocadas pelas pessoas que decidiram, sendo denunciadas como carentes de fundamentação linguística, requisito essencial para compor grupo especializado e capacitado para tarefas decisórias desse nível. E tudo isso sentido e apreendido por ele no convívio de grande efervescência linguística e, por que não, política e jurídica.

E nosso "estrangeiro" (primeiro autor deste artigo) foi conhecer outro "pagos portugueses": Faculdade de Direito da Universidade Nova de Lisboa. Mais desafios o esperavam: um curso de Português Jurídico para ministrar e um pós-doutorado para cursar. Essa experiência justamente no momento da implementação do (des)Acordo no Brasil trazem um efeito concreto e do absurdo muito mais latente.

A língua é a mesma, mas o idioma é diferente. Muitos estudos desse itinerante linguista para aplicar em uma sala aula, mas sua experiência ontológica na academia já o preveniam das dificuldades de comunicação que poderiam ocorrer. Diferenças já depreendidas foram objeto de discussão e reflexão, tornando o processo de ensino com uma riqueza linguística para os dois lados.

E foi lá, em sala de aula, que os "porquês" 27 se apresentaram com diferenças na sua aplicação. O termo "absurdo" não foi dito, mas ficou subentendido na exposição da sintaxe portuguesa e da brasileira. Sim, porque a necessidade de fundamentação linguística se fazia presente para os dois idiomas. Certamente que a intenção do "estrangeiro professor" era provocar os alunos para que a absurdidade viesse à tona. E veio, do verbo 'vir', agora sem acento agudo na paroxítona porque, absurdamente, a "reforma ortográfica" o aboliu por entender que ditongos abertos não podem mais ser acentuados nesses casos. Entenderam

\footnotetext{
${ }^{27}$ PRIBERAM, dicionário português online: $\mathrm{O}$ "porquê" também pode ser pronome interrogativo. Exemplo: Você ficou furioso porquê?; No Brasil, a forma é "por que" (preposição + pronome relativo).
} 
errado! Ditongos abertos eram todos acentuados e agora há essa restrição. Por quê? Não há justificativa plausível para tirar de um e deixar em outros, sendo que a pronúncia e tonicidade são as mesmas. Só lembrando: essa foi uma das atrocidades linguísticas denunciadas. Teriam decidido melhor se tivessem abolido de todos, ficaria sem restrição alguma.

Quanto à absurdidade anterior a respeito dos dois idiomas, ficou bem esclarecido que as diferenças idiomáticas são produzidas por culturas diferentes e pelo povo de uma comunidade específica. Por isso também a unificação perde o seu objetivo principal, que é o de simplificar a comunicação dos países lusófonos.

Diante dessas relações comunicativas, sem entrar no conteúdo programático do curso, geraram outro convite: palestra-debate na própria faculdade de Direito para alunos da graduação, mestrado e doutorado, assim como professores da instituição. Estudantes portugueses, brasileiros, angolanos, moçambicanos e de outras nacionalidades. Todos estavam lá para ouvir o itinerante estrangeiro que veio do Brasil, país que foi um dos principais signatários do famigerado acordo. Diante do título "(Des)acordo ortográfico”, a surpresa, pois entendiam, pelo "senso comum" que brasileiro defenderia o acordo. Esse senso comum é proveniente de uma pretensa lógica silogista, na verdade um sofisma da regra: 'O acordo é brasileiro; o debatedor é brasileiro; Logo, é a favor do acordo'. Falácia da Regra do Modus Ponens: afirmou o termo consequente para concluir o termo antecedente.

Não havia no público que assistiu à palestra-debate alguém que fosse a favor do acordo. Segundo os que entraram no debate, precisavam ouvir os argumentos contrários a essa unificação. As dificuldades para o acordo foram explicitadas: 1. Questões culturais de cada país; reunião periódica sobre as adequações ortográficas para a unificação; fonética particular de um grupo de falantes que possivelmente implique mudança ortográfica; e principalmente critérios para se chegar ao bom senso. E a reflexão foi provocada pelos questionamentos: 1. Por que unificar a ortografia se a "língua", patrimônio de um povo, continuará diferente?; 2. Por que cada país precisa abdicar de determinadas grafias para a unificação?; e Se todos perdem um pouco, todos perdem algo. Por que perder? Uma nova experiência ocorreu: a certeza de que pessoas com bom nível de discernimento são unânimes em não aceitar algo que é imposto arbitrariamente e sem plausibilidade. 
Além disso, sabe-se que um diálogo entre nações e povos pressupõe igualdade, mas tambem distinção, pois sem a igualdade não é possível um fundamento comum para a comunicação, e sem a distinção, não há sequer necessidade de comunicação e diálogo. A diferença, portanto, é desejável, respeita as nuances culturais, fundamentais e riquíssimas para um diálogo e resperito multicultural. Enfim, a pluralidade não é apenas desejável, mas condição (grifo importante) para a liberdade do diálogo e de uma chegada a consensos de forma voluntária e autônoma. ${ }^{28} \mathrm{E}$ há algo que ainda precede tudo isso, que precede o consenso e o possibilita: o reconhecimento do outro. E onde está esse reconhecimento em meio a tal (des) Acordo?

Dessa jornada, descobriu-se na rede social um movimento coordenado e monitorado pelo jurista Ivo Miguel Barroso ${ }^{29}$ contra esse cruel acordo. É um referendo popular que visa derrubá-lo via judicial. Muita informação diária que o coloca como um dos críticos com armamento argumentativo suficiente para poder fazer o mesmo em sua terra de origem: o Brasil. Pretensão que pode ser tornar realidade.

Os cidadãos de língua portuguesa, brasileiros, mas estrangeiros em relação ao idioma português, continuarão a experienciar a comunicação por todos os cantos de sua terra além-mar, com a certeza de que a unificação é distópica e perniciosa à comunicação humana, considerando esta para qualquer país que pretenda unificar a sua língua.

Acrescido a tudo isso, há essa desgraça que não cessa nunca de ameaçar a todos, a prepotência humana pela pretensão universalista, que esquece que o próprio pluralismo é garantia de liberdade (lembrando os próprios fundamentos dos direitos humanos, que deveriam ser aqui aproveitados pois constituem uma base legítima como guia para diversidade e respeito a ela). É a partir da diversidade, do pluralismo, do respeito ao multiculturalismo e às variadas nuances de multiplicidades culturais já que a segurança excessiva sempre destruiu a liberdade necessária, que a liberdade é garantida, e a ideia de "vida boa" inerente à liberdade. ${ }^{30}$

\footnotetext{
${ }^{28}$ KRETSCHMANN, Angela. Cultura, Direitos Humanos e Emancipação Latino-Americana. IMED: Passo Fundo: 2013. p. 89.

${ }^{29} \mathrm{Na}$ rede social "Facebook", o endereço é https://www.facebook.com/ivomiguelbarroso.

${ }^{30}$ KRETSCHMANN, Angela. Cultura, Direitos Humanos e Emancipação Latino-Americana. IMED: Passo Fundo: 2013. p. 84.
} 
O (des) Acordo linguístico é apenas um exemplo atual de que a opressão vigora nos mais distintos campos da atuação humana. A história humana é sempre uma obra aberta, e enclausurá-la, inclusive por meio de um "Acordo" linguístico, não deixa de nos trazer aquele arrepio na espinha relativo a tantas barbáries ocorridas sempre em que se buscou enclausurar essa mesma história humana. Ninguém pensou na violência que se pratica contra os direitos culturais garantidos pelos Direitos Humanos e pelas diversas cartas constitucionais? Há, por acaso, uma classe que "brinca" com as palavras, as culturas e não é atingida por tais direitos, e não é obrigada a respeitá-los?

\section{CONSIDERAÇÕES FINAIS}

1. O protagonista da obra de Camus, Mersault, condenado por um tribunal não pelo crime que cometeu, mas pela sua conduta social, é estigmatizado pela maioria da crítica jurídica em função de que fica alheio aos acontecimentos sociais e de que não luta para se defender. Ele reage sim. É preciso encarar a obra não pelo "senso comum”, mas pelo senso de quem atentamente a analisa, sem a indução dos que já a leram antes e que seguem o que a maioria dos artigos e resenhas dispõe ao leitor.

2. O absurdo não está nas atitudes de Meursalt, está na conduta da sociedade e estabelece falsas premissas

3. A exemplo de Mersault, que reage às incoerências e absurdidades, mesmo de maneira branda, os autores deste artigo reagem expondo seus argumentos principalmente no meio acadêmico. Mas, diante da arbitrariedade de quem decide, não houve como mudar as sentenças. Um foi para a prisão, literalmente; os outros foram condenados a escrever livros, artigos e ministrar aulas da "nova ortografia" (no caso do primeiro autor).

4. Acordo Ortográfico foi imposto, não pela necessidade de adequação ao meio, mas pela falácia de uma aplicação autoritária da Academia Brasileira de Letras juntamente com o governo brasileiro; 
5. Duas narrações estiveram no eixo condutor dessa pretensa analogia a convergir para que a contrassensualidade se apresentasse como forma de propiciar aos leitores uma reflexão do absurdo que as pessoas, através de suas "instituições", podem cometer, ou por ignorância, ou por interesse particular, possivelmente ambos, a partir de situações que possam comprometer a sociedade como um todo.

6. Com relação ao relato do caso do prefeito de Biririba, o autor é muito coerente em su a crônica para que a absurdidade seja bem entendida, tanto pelo lado do prefeito, seu personagem, como pelo de si mesmo.

7. Uma expressão, seja ela brasileira ou portuguesa, permite a pluralidade significativa com a mesma língua de origem, a portuguesa, porque as diferenças culturais refletem tanto no idioma como no dialeto. Dialeto aqui está sendo metodologicamente utilizado para fazer oposição ao idioma.

8. Há um referendo popular contra o acordo ortográfico em Portugal. São muitíssimas manifestações. Na verdade, o cidadão português deu-se conta que o prejuízo maior não foi do brasileiro e sim deles mesmos.

9. Finalmente, os "deuses" da criação e imposição das palavras parecem estar totalmente alheios à existência dos direitos humanos e culturais, os quais, como construção histórica e legítima, veem a diferença, a pluralidade, e principalmente o respeito à língua como uma base cultural que merece ser reverenciada, pois constitui condição para o diálogo e a existência da liberdade. Onde a liberdade? Onde o diálogo? Onde a pluralidade? Onde a diferença que nos aproxima, que permite o reconhecimento pelo respeito às nossas significantes diferenças? Eis o que merece ser lembrado: existem direitos humanos construídos historicamente - que servem para esclarecer os proponentes de um tal "acordo" - sobre as tragédias humanas já ocorridas com todas as tentativas de homogeneização e universalização.

\section{REFERÊNCIAS BIBLIOGRÁFICAS}

ACADEMIA DAS CIÊNCIAS DE LISBOA - ACL. Vocabulário Ortográfico Atualizado da Língua Portuguesa. Lisboa: Imprensa Nacional-Casa da Moeda, 2012. 
ACADEMIA BRASILEIRA DE LETRAS - ABL. Vocabulário Ortográfico da Língua Portuguesa. 5. Ed. São Paulo: Global Editora, 2009.

CAMUS, Albert. O Estrangeiro. Tradução de Valerie Rumjanek. Rio de Janeiro : Record, 1977.

CONCEIÇÃO, Celso Augusto N. da (2015). “(Des)acordo Ortográfico”. Disponível em < http://www.fd.unl.pt/Anexos/10386 4.pdf>. Acesso em $15 \mathrm{dez} 2015$.

\& MOREIRA, Edelvira A. da Silva (2013). O Alienista e o Acordo Ortográfico de 2009: insanidade compartilhada. Disponível em $<$ http://ojs.cesuca.edu.br/index.php/dialogosdodireito/article/view/391/192>. Acesso em 03 jan 2016, p. 188-197.

HOUAISS ELETRÔNICO. Dicionário Houaiss da Língua Portuguesa. Rio de Janeiro: Editora Objetiva, 2009.

KRETSCHMANN, Angela. Cultura, Direitos Humanos e Emancipação Latino-Americana. IMED: Passo Fundo: 2013.

KRETSCHMANN, Angela; WIEDEMANN, Ney. Argumentação Jurídica IN KRETSCHMANN, Angela, Org. Formação Jurídica II. Florianópolis, 2014.

MARCONDES, Danilo e JAPIASSÚ, Hilton. Dicionário básico de filosofia. 4.ed. Rio de Janeiro: Zahar, 2006.

MOREAU, Raul. A lógica do absurdo. Porto Alegre: Editora do Autor, 2005.

PRIBERAM. Dicionário Priberam da Língua Portuguesa (DPLP). Disponível em < https://www.priberam.pt/DLPO/>. Acesso em 04 nov 2015.

REFERENDO AO ACORDO ORTOGRAFICO DE 1990. Disponível em https://www.facebook.com/groups/914281441947403/?fref=ts. Acesso em 07/01/2016.

WARAT. Luís Alberto. As falácias jurídicas. Revista Sequência : estudos jurídicos e políticos da Universidade Federal de Santa Catarina. V. 06, n 10, 1985, p. 123-128.

WORDPRESS. Referendo ao "Acordo Ortográfico de 1990”. Disponível em < https://referendoao90.wordpress.com/>. Acesso em 7 jan 2016.

Volume I. Porto Alegre: Sérgio Antônio Fabris Editor, 1997. 